\title{
Plasmodium falciparum: linkage disequilibrium between loci in chromosomes 7 and 5 and chloroquine selective pressure in Northern Nigeria
}

\author{
I. S. ADAGU* and D. C. WARHURST \\ Department of Infectious and Tropical Diseases, London School of Hygiene and Tropical Medicine, Keppel Street, \\ London WCIE $7 H T$, UK
}

(Received 17 fanuary 2001 ; revised 26 March 2001 ; accepted 29 March 2001)

\section{SUMMARY}

In view of the recent discovery (Molecular Cell 6, 861-871) of a (Lys76Thr) codon change in gene pfcrt on chromosome 7 which determines in vitro chloroquine resistance in Plasmodium falciparum, we have re-examined samples taken before treatment in our study in Zaria, Northern Nigeria (Parasitology 119, 343-348). Drug resistance was present in $5 / 5$ cases where the $p$ fcrt $76 \mathrm{Thr}$ codon change was seen ( $100 \%$ positive predictive value). Drug sensitivity was found in $26 / 28$ cases where the change was absent $(93 \%$ negative predictive value). Allele pfcrt $76 \mathrm{Thr}$ showed strong linkage disequilibrium with $p f m d r 1$ Tyr86 on chromosome 5, more complete than that between $p f c r t$ and $c g 2$ alleles situated between recombination cross-over points on chromosome 7. Physical linkage of $c g 2$ with $p f c r t$ may account for linkage disequilibrium between their alleles but in the case of genes $p f m d r 1$ and $p f c r t$, on different chromosomes, it is likely that this is maintained epistatically through the selective pressure of chloroquine.

Key words: linkage disequilibrium, Plasmodium falciparum, chloroquine resistance, malaria, Nigeria.

\section{INTRODUCTION}

Resistance to chloroquine in Plasmodium falciparum developed in South East Asia and South America about 10 years after the introduction of the antimalarial in the $1950 \mathrm{~s}$, and reached Africa by the late 1970s (Peters, 1998). In spite of its reduced efficacy, chloroquine is still the first-line anti-malarial drug in most of Africa for reasons of cost, and also because widespread partial immunity in symptomatic older children and adults enhances the effect of the drug (Sokhna et al. 1997; Djimde et al. 2001).

Nevertheless, resistance is having a major impact. Emergence of chloroquine resistance in Senegal, West Africa, over 12 years was associated with at least a 2-fold higher risk of death from malaria in children under 10 years old (Trape et al. 1998). In East Africa, Kenyan children under 5 admitted to hospital for malaria are reported to have a $33 \%$ case fatality rate if given chloroquine treatment in contrast to $11 \%$ for sulfadoxine-pyrimethamine, quinine or 5-day co-trimoxazole (Zucker et al. 1996).

In $P$. falciparum, weaker or stronger associations (Foote et al. 1990) are seen between chloroquine resistance and sequence changes in an MDR type protein, Pgh1, localized in the blood-stage parasite's lysosomal membrane (Cowman et al. 1991), and specified by $p f m d r 1$ on chromosome 5 . However, the

* Corresponding author: Tel: +44 207927 2324. Fax: +44 207637 0248. E-mail: Ipemida.Adagu@1shtm.ac.uk progeny of a genetic cross showed a link between chloroquine resistance and a locus on chromosome 7 (Wellems et al. 1990). Su et al. (1997) linked resistance to changes in the $\operatorname{cg} 2$ gene on this chromosome, which specifies a protein of unknown function (Wellems et al. 1998). Still the correlation with resistance failed to reach $100 \%$, and transfection of mutated $c g 2$ did not transfer it (Fidock $e t$ al. 2000a). A lysine to threonine ( $\mathrm{K}$ to $\mathrm{T}$ ) change in codon 76 of a new gene, pfcrt (also on chromosome 7) specifying the lysosomal transmembrane protein PfCRT, gave a complete association with in vitro chloroquine resistance of P. falciparum isolates from Africa, South East Asia and South America (Fidock et al. $2000 \mathrm{~b}$ ). Wild-type PfCRT resembles a protein reported to facilitate the transport of organic cations (Zhang et al. 1997) and may normally be involved in the efflux of basic amino acids or short basic peptides (Eggleson, Duffin \& Goldberg, 1999) from the lysosome.

Before the discovery of pfcrt, we (Adagu \& Warhurst, 1999) examined polymorphisms associated with chloroquine resistance in $p f m d r 1$ and $c g 2$ on chromosomes 5 and 7 in samples taken before chloroquine treatment of a group of children in Zaria, Northern Nigeria. The Asn 86 Tyr codon change in pfmdr1, the Gly 281 Ala mutation and the Dd2-type $\kappa$ repeat of $c g 2$, were significantly associated, suggesting co-selection by the drug. Polymorphisms examined were highly predictive for drug resistance, but associations were incomplete. 
In order to complete our earlier study, we have reexamined our collection in Zaria for polymorphism at codon 76 of $p f c r t$, determined the value of this polymorphism in prediction of drug resistance in this geographical location, its association with polymorphisms in cg2 on the same chromosome and with polymorphisms in pfmdr1 on chromosome 5 . We find that $p f c r t$ Thr76 on chromosome 7 is highly predictive for chloroquine resistance, and in strong linkage disequilibrium with $p f m d r 1 \mathrm{Tyr} 86$ on chromosome 5, more complete than the degree of pfcrt 76 linkage with $\mathrm{cg} 2$ alleles situated between recombination cross-over points on the same chromosome. Physical linkage of $c g 2$ with $p f c r t$ may account for linkage disequilibrium between their alleles but in the case of genes $p f m d r 1$ and $p f c r t$, on different chromosomes, it is likely that, in this geographical location, linkage is maintained epistatically through the selective pressure of chloroquine.

\section{MATERIALS AND METHODS}

Parasite samples examined in this study were those previously characterized for chloroquine resistance associated sequence variations in $p f m d r 1$ and $c g 2$ genes (Adagu \& Warhurst, 1999). The samples were from Zaria, an area of North Central Nigeria located in the Guinea Savannah belt. Malaria in this area is holoendemic and in 1993 when the samples were collected, $20 \%$ of infections showed resistance to chloroquine, mainly at the RI level (Adagu et al. 1995). Symptomatic children were aged from 7 months to 11 years (mean $5 \cdot 2 \pm 3$ years). Geometric mean parasitaemia on admission was $20629 / \mathrm{mm}^{3}$, ranging from 1000 to 55353. Samples F91, F130, F170 and F183 (3 sensitive and 1 resistant) examined in our previous study (Adagu \& Warhurst, 1999) were no longer available. A total of 35 samples remained.

Professor C. Plowe kindly gave us the protocol for a nested PCR/RFLP (Djimde et al. 2001: GenBank accession number AF233068) for detection of the $76^{\mathrm{AAA} \rightarrow \mathrm{ACA}}\left(76^{\mathrm{Lys} \rightarrow \mathrm{Thr}}\right)$ mutation in pfcrt. Nest I primers, 5' CCG TTA ATA ATA AAT ACA CGC AG 3' (forward) and 5' CGG ATG TTA CAA AAC TAT AGT TAC C $3^{\prime}$ (reverse) and the nest II primers, 5' TGT GCT CAT GTG TTT AAA CTT 3' (forward) and 5' CAA AAC TAT AGT TAC CAA TTT TG 3' (reverse) were used as described in the protocol. The PCR mix contained standard $\mathrm{KCl}$ buffer, 1.25 U Taq polymerase (Bioline), dNTPs (200 $\mu \mathrm{M}$ each), primers (1 $\mu \mathrm{M}$ each) and for nest I reaction a sector of glass-fibre membrane DNA source or $1 \mu \mathrm{l}$ of nest I product for nest II reaction. Nest I reaction $\left(94{ }^{\circ} \mathrm{C}, 30 \mathrm{~s} ; 56{ }^{\circ} \mathrm{C}\right.$, $30 \mathrm{~s}$ and $\left.60^{\circ} \mathrm{C}, 1 \mathrm{~min}\right)$ was cycled 45 times with initial denaturation and final extension steps of $94^{\circ} \mathrm{C}, 3 \mathrm{~min}$ and $60^{\circ} \mathrm{C}, 3 \mathrm{~min}$ respectively. Nest II reaction $\left(94{ }^{\circ} \mathrm{C}, 30 \mathrm{~s} ; 48{ }^{\circ} \mathrm{C}, 30 \mathrm{~s}\right.$ and $\left.65^{\circ} \mathrm{C}, 3 \mathrm{~min}\right)$ was cycled 30 times with an initial denaturation and final extension steps of $94^{\circ} \mathrm{C}, 5 \mathrm{~min}$ and $65^{\circ} \mathrm{C}$, 3 min respectively. Nest II product was restricted at $50{ }^{\circ} \mathrm{C}$ with $0.5 \mathrm{U}$ of $A$ po 1 restriction enzyme following the manufacture's protocol and the resulting digest was resolved in a $2 \%$ agarose gel.

\section{Analysis of results}

The diagnostic parameters of sensitivity, specificity, and positive and negative predictive value were calculated as follows.

Sensitivity. Percentage of resistant outcomes correctly predicted by the positive test result. $(\mathrm{TP} / \mathrm{TP}+\mathrm{FN}) \times 100,($ where $\mathrm{TP}=$ True Positives: $\mathrm{FN}=$ False Negatives: $\mathrm{TN}=$ True Negatives: FP $=$ False positives).

Specificity. Percentage of sensitive outcomes correctly predicted by the negative test result $(\mathrm{TN} / \mathrm{TN}+\mathrm{FP}) \times 100$.

Positive predictive value. Percentage of positive tests correctly predicting a resistant outcome. $(\mathrm{TP} / \mathrm{TP}+\mathrm{FP}) \times 100$.

Negative predictive value. Percentage of negative tests correctly predicting a sensitive outcome. $(\mathrm{TN} / \mathrm{TN}+\mathrm{FN}) \times 100$.

Linkage disequilibrium values were calculated by a pairwise analysis of the loci studied using the method described by Maynard Smith (1989) for $D^{\prime}$, and that of Hill \& Robertson (1968) for $r^{2}$. Both $D^{\prime}$ and $r^{2}$ have values of -1 to +1 , and the closer they approach to -1 or 1 , the greater the linkage disequilibrium between loci. Prevalences were used to estimate frequencies by assuming that the presence of a single allele in a sample is indicative of infection with a single clone. Thus mixed alleles were excluded from the analysis. Significance of associations was estimated using 2 by 2 tables for $\chi^{2}$ from the EpiInfo 6 StatCalc Program.

Associations between gene polymorphisms and chloroquine resistance were also determined by analysis of $2 \times 2$ tables using StatCalc. It was not possible to calculate all diagnostic parameters for pre-treatment data from the paper of Djimde et al. (2001) on the basis of information supplied for the whole population. However, data in Table 2 and in other parts of the text in their publication were usable. Assuming a group of 200 patients, it can be deduced that treatment would fail in $29(14.5 \%)$ and succeed in $171(85.5 \%)$. A diagnostic comparison table can then be drawn as follows.

The calculated sensitivity of $91.8 \%$ is reported as $92 \%$ in their table, validating the calculation. 
Table 1. Diagnostic table calculated from Djimde et al. (2001)

\begin{tabular}{lllc}
\hline \hline MALI & T76 mutant & K76 wild type & Total \\
\hline Resistant & $26 \cdot 622$ & $2 \cdot 378$ & 29 \\
& True positives & False negatives & \\
Sensitive & 63.954 & $107 \cdot 046$ & 171 \\
& False positives & True negatives & \\
Total & $90 \cdot 576$ & $109 \cdot 424$ & 200 \\
$\%$ Sensitivity & $91 \cdot 8$ & & \\
$\%$ Specificity & $62 \cdot 6$ & & \\
$\%$ PPV & $29 \cdot 4$ & & \\
$\%$ NPV & $97 \cdot 8$ & & \\
\hline \hline
\end{tabular}

RESULTS

The chloroquine susceptibility and the $p f m d r 1 / c g 2$ profiles of the parasites have been reported elsewhere (Adagu et al. 1995; Adagu \& Warhurst, 1999). Table 2 shows the $2 \times 2$ tables and analyses of the association between resistance and polymorphisms. Two samples from patients with 'resistant' infections are of particular concern, because they showed neither the mutant $p f c r t$ nor the mutant $p f m d r 1$. One sample (F142) was from an infection found resistant in vitro. In view of the growing body of evidence unequivocally linking mutant $p f c r t$ with in vitro chloroquine resistance, it is unlikely that this is a correct assignment. However, Djimde et al. (2001) have reported that parasites from $8 \%$ of failed treatments in their study in Mali did not reveal the pfort mutation in the pre-treatment sample, although it appeared in all the recurring infections examined. We have no valid reason to exclude this infection from our calculations. The other (F211) recurred on day 28 and could have been a re-infection. As reported by Adagu \& Warhurst (1999), lack of posttreatment samples in our study did not permit PCR analysis which could have indicated cases where recurrences were reinfections. As argued above, we have also included this result in the calculations. All 28 samples from chloroquine-sensitive infections carried wild-type pfcrt codon $76\left(76^{\mathrm{AAA}}\right)$.
Table 3 shows the measures of linkage disequilibrium in paired alleles of $p f c r t, c g 2$ and $p f m d r 1$. Alleles of $p f c r t$ and $p f m d r 1$, on different chromosomes, show the highest degree of linkage disequilibrium $\left(D^{\prime}=1 \quad[0.99-1 \cdot 01], \quad r^{2}=0.81\right.$ [0.68-0.94] $P=0 \cdot 00002)$. This reflects the fact that in all cases where mutant pfcrt was seen, there was also mutant $p f m d r 1$, although in 1 (chloroquinesensitive) sample, mutant $p f m d r 1$ was found without mutant pfcrt. Disequilibrium between $c g 2281$ and pfcrt76, both on chromosome 7 , had a significantly lower value for the more stringent $r^{2}$ parameter than was seen between $p f m d r 186$ and $p f c r t 76$ on different chromosomes. Surprisingly, both linkage measures between $c g 2281$ and $c g 2 \kappa$,on the same gene, were significantly lower than those between pfmdr 186 and pfcrt 76 .

\section{DISCUSSION}

The presence of pfcrt 76Thr predicted chloroquine resistance in our study $(100 \%$ positive predictive value). Specificity and positive predictive value using either of 2 loci on $c g 2$ were significantly inferior to those obtained using pfcrt 76 or $p f m d r 1$ 86. In their treatment trial in endemic malaria in Mali, Djimde et al. (2001) examined the association between chloroquine resistance and mutations in pfcrt and pfmdr1. Sensitivity of the test was $92 \%$ and specificity was $63 \%$. In the Mali study, the percentage of mutant pfcrt test results predicting treatment failures (positive predictive value) is estimated by us as $29.4 \%$, whilst $98 \%$ of non-mutant test results predicted successful treatments (negative predictive value is $98 \%$ ). When pfcrt $76 \mathrm{Thr}$ and pfmdr1 86Tyr were considered together, specificity increased to $78 \%$, but sensitivity fell from $92 \%$ to $73 \%$. Positive predictive value improved appreciably when patients under 10 years of age were considered separately.

Recent evidence suggests that changes in pfmdr 1 taking place on a background of another determinant, presumably a change in $p f c r t$, are important for higher levels of chloroquine resistance. Transfection of pfmdr1 mutants would only enhance

Table 2. Utility of the alleles studied for predicting chloroquine resistance

\begin{tabular}{|c|c|c|c|c|c|c|c|c|}
\hline \multirow{2}{*}{$\begin{array}{l}\text { Resistance } \\
\text { and alleles }\end{array}$} & \multicolumn{2}{|c|}{$2 \times 2$ Table } & \multirow[b]{2}{*}{$P$} & \multirow{2}{*}{$\begin{array}{l}\text { Sensitivity }(\%) \\
(95 \% \text { limits })\end{array}$} & \multirow{2}{*}{$\begin{array}{l}\text { Specificity }(\%) \\
(95 \% \text { limits })\end{array}$} & \multirow{2}{*}{$\begin{array}{l}\text { PPV (\%) } \\
(95 \% \text { limits })\end{array}$} & \multirow{2}{*}{$\begin{array}{l}\text { NPV }(\%) \\
(95 \% \text { limits })\end{array}$} & \multirow[b]{2}{*}{$\mathrm{PPV}+\mathrm{NPV} / 2$} \\
\hline & RES & SENS & & & & & & \\
\hline $\begin{array}{l}\text { pfcrt 76T } \\
\text { pfcrt } 76 \mathrm{~K}\end{array}$ & $\begin{array}{l}5 \\
2\end{array}$ & $\begin{array}{r}0 \\
28\end{array}$ & $0 \cdot 00007$ & $71(38-105)$ & $100(99-101)$ & $100(98-102)$ & $93(84-103)$ & $96 \cdot 5(90-103)$ \\
\hline $\begin{array}{l}\mathrm{Cg} 2281 \mathrm{~A} \\
\mathrm{Cg} 2281 \mathrm{G}\end{array}$ & $\begin{array}{l}5 \\
2\end{array}$ & $\begin{array}{r}6 \\
22\end{array}$ & $0 \cdot 02$ & $71(38-105)$ & $79(63-94)$ & $46(9-82)$ & $92(81-102)$ & $69(47-91)$ \\
\hline $\begin{array}{l}\mathrm{Cg} 2 \kappa \mathrm{Dd} 2 \\
\mathrm{Cg} 2 \kappa \mathrm{Hb} 3\end{array}$ & $\begin{array}{l}6 \\
1\end{array}$ & $\begin{array}{r}7 \\
21\end{array}$ & $0 \cdot 006$ & $86(60-116)$ & $75(60-91)$ & $46(9-83)$ & $96(77-88)$ & $71(49-93)$ \\
\hline $\begin{array}{l}\text { pfmdr1 } 86 \mathrm{Y} \\
\text { pfmdr1 } 86 \mathrm{~N}\end{array}$ & $\begin{array}{l}5 \\
2\end{array}$ & $\begin{array}{r}1 \\
27\end{array}$ & $0 \cdot 0004$ & $71(38-105)$ & $96(90-103)$ & $83(56-111)$ & $93(84-103)$ & $88(73-104)$ \\
\hline
\end{tabular}


Table 3. Association and linkage disequilibrium between paired alleles of $p f c r t$ and $c g 2$ on chromosome 7 , and $p f m d r 1$ on chromosome 5

\begin{tabular}{|c|c|c|c|c|c|c|}
\hline & & & $\mathrm{D}^{\prime}(95 \%$ limits $)$ & $r^{2}(95 \%$ limits $)$ & $P$ & $n$ \\
\hline Paired alleles & pfcrt $76 \mathrm{~T}$ & pfcrt $76 \mathrm{~K}$ & \multirow{3}{*}{$1(0 \cdot 99-1 \cdot 01)$} & \multirow{3}{*}{$0 \cdot 81(0 \cdot 68-0 \cdot 94)$} & \multirow{3}{*}{$0 \cdot 00002$} & \multirow{3}{*}{35} \\
\hline pfmdr1 86Y & 5 & & & & & \\
\hline pfmdr1 86N & 0 & 29 & & & & \\
\hline $\operatorname{cg} 2281 \mathrm{~A}$ & $\begin{array}{l}5 \\
0\end{array}$ & $\begin{array}{r}6 \\
24\end{array}$ & $1(0 \cdot 99-1 \cdot 01)$ & $0 \cdot 36(0 \cdot 20-0 \cdot 52)$ & $0 \cdot 001$ & 35 \\
\hline $\begin{array}{l}\operatorname{cg} 2281 \mathrm{G} \\
\operatorname{cg} 2 \kappa \mathrm{Dd} 2\end{array}$ & $\begin{array}{l}0 \\
5\end{array}$ & $\begin{array}{r}24 \\
3\end{array}$ & \multirow{2}{*}{$1(0 \cdot 99-1 \cdot 01)$} & \multirow{2}{*}{$0.55(0 \cdot 37-0.73)$} & \multirow[t]{2}{*}{$0 \cdot 0004$} & \multirow[t]{2}{*}{30} \\
\hline $\operatorname{cg} 2 \kappa \mathrm{Hb} 3$ & 0 & 22 & & & & \\
\hline $\begin{array}{l}\text { Paired alleles } \\
\text { cg2 281A }\end{array}$ & $\underset{6}{p f m d r 186 \mathrm{Y}}$ & $\underset{5}{p f m d r 1} 86 \mathrm{~N}$ & \multirow{4}{*}{$\begin{array}{l}1(0 \cdot 99-1 \cdot 01) \\
0 \cdot 77(0 \cdot 62-0 \cdot 92)\end{array}$} & \multirow{4}{*}{$\begin{array}{l}0.45(0.29-0.62) \\
0.41(0.23-0.59)\end{array}$} & \multirow{2}{*}{$0 \cdot 0003$} & \multirow{2}{*}{35} \\
\hline $\operatorname{cg} 2281 \mathrm{G}$ & 0 & 24 & & & & \\
\hline $\operatorname{cg} 2 \kappa \mathrm{Dd} 2$ & 5 & 3 & & & $0 \cdot 002$ & 30 \\
\hline $\operatorname{cg} 2 \kappa \mathrm{Hb} 3$ & 1 & 21 & & & & \\
\hline Paired alleles & $c g 2281 \mathrm{~A}$ & $c g 2281 \mathrm{G}$ & \multirow{3}{*}{$0 \cdot 50(0 \cdot 32-0 \cdot 68)$} & \multirow{3}{*}{$0 \cdot 41(0 \cdot 23-0 \cdot 59)$} & \multirow{3}{*}{$0 \cdot 001$} & \multirow{3}{*}{30} \\
\hline $\operatorname{cg} 2 \kappa \mathrm{Dd} 2$ & 7 & 1 & & & & \\
\hline$c g 2 \kappa \mathrm{Hb} 3$ & 4 & 18 & & & & \\
\hline
\end{tabular}

chloroquine resistance in clones now known to carry mutant pfcrt (Reed et al. 2000). Unfortunately, this possibility has not been tested directly for codon 86 allelic forms of pfmdr1. We have shown here that linkage disequilibrium between $c g 2$ alleles and $p f c r t$, both on chromosome 7, and even for $\operatorname{cg} 2281$ and the $\operatorname{cg} 2 \kappa$ repeat size polymorphism on the same gene, is less marked in these Northern Nigerian samples than for pfcrt with $p f m d r 1$, on different chromosomes. Duraisingh et al. (2000) reported linkage disequilibrium in Gambian samples between the $c g 2 \omega$ repeat size polymorphism and $p f m d r 186\left(D^{\prime}=\right.$ $\left.0 \cdot 87: r^{2}=0 \cdot 27\right)$, strikingly this was higher than the linkage between $p f m d r 1$ codons 86 and 184, separated by only 296 base pairs. Duraisingh et al. (2000) concluded that the linkage disequilibrium between the alleles of genes $p f m d r 1$ and $c g 2$ indicated that these or closely related loci are important determinants of chloroquine resistance, their linkage being maintained epistatically through selection by chloroquine. Adagu \& Warhurst (1999) had also reported linkage between $p f m d r 186$ and $c g 2281$ and $\kappa$ polymorphisms, with the same conclusion. However, our additional linkage analysis includes both $c g 2$ and $p f c r t$, which are located approximately $10 \mathrm{~K}$ base pairs apart ( $0 \cdot 6$ centimorgans: Su et al. 1999) on chromosome 7 , in a $36 \mathrm{~K}$ base-pair sequence between recombination cross-over points mapped in the $\mathrm{Hb} 3 \times \mathrm{Dd} 2$ genetic cross (Su et al. 1997). This location suggests that any linkage disequilibrium between their alleles is related to physical linkage and not to epistatic factors. It is highly likely that the linkage disequilibrium we demonstrated earlier between $p f m d r 1$ and $c g 2$ depends on the physical linkage of $p f c r t$ with $c g 2$ and that the stronger linkage we have now shown between pfcrt and pfmdr1 on chromosome 5 is maintained epistatically by chloroquine. Selection for $p f m d r 186 \mathrm{Tyr}$ by chloroquine and amodiaquine was shown in a treatment trial (Duraisingh et al. 1997). The recent study by Djimde et al. (2001) confirmed selection of both pfmdr1 $86 \mathrm{Tyr}$ and pfcrt $76 \mathrm{Thr}$ by chloroquine treatment.

It must be emphasized that an association between pfmdr1 and chloroquine resistance has not been confirmed in all studies especially those from other geographical areas (for example Sudan-Awad El Kariem, Miles \& Warhurst, 1992: Thailand-Wilson et al. 1993). Currently it appears that West and Central Africa (Adagu et al. 1996; Adagu \& Warhurst, 1999; Basco et al. 1995; Djimde et al. 2001; Duraisingh et al. 1997, 2000; Grobusch et al. 1998) are the main areas where an association (not absolute and presumably depending on the presence of mutated $p f(r t)$ between $p f m d r 1$ codon changes and chloroquine resistance can reliably be demonstrated. In Brazil too, where chloroquine resistance has been present about 20 years longer than in Africa, $p f m d r 1$ with altered codons is predominant (Povoa et al. 1999) and mutated pfcrt has been demonstrated in in vitro resistant isolates (Fidock et al. 2000b).

We would like to thank Professors Tom Wellems and Chris Plowe for communication of unpublished data, in letters and by generous submissions to GeneBank, and for providing the PCR/RFLP protocol used for pfcrt in this study. I.S.A. is supported on a ROMARK project. D.C.W. is supported by the Public Health Laboratory Service, UK.

\section{REFERENCES}

ADAGU, I. S. \& WARHURST, D. C. (1999). Association of $c g 2$ and $p f m d r 1$ genotype with chloroquine resistance in field samples of Plasmodium falciparum from Nigeria. Parasitology 119, 343-348. 
ADAGU, I. S., WARHURST, D. C., OGAla, W. N., ABDU-AGUYE, I., AUDU, L. I., BAMgBola, F. O. \& OVWigho, U. B. (1995). Antimalarial drug response of Plasmodium falciparum from Zaria, Nigeria. Transactions of the Royal Society of Tropical Medicine and Hygiene 89, 422-425.

ADAGU, I. S., DIAS, F., PINHEIRO, L., ROMBO, L., DO Rosario, v. \& WARHURST, D. C. (1996). Guinea Bissau: association of chloroquine-resistance of Plasmodium falciparum with the Tyr86 allele of the multiple drug resistance gene Pfmdr1. Transactions of the Royal Society of Tropical Medicine and Hygiene 90, 90-91. AWAD-El-Kariem, F. M., Miles, M. A. \& WARhURST, D. C. (1992). Chloroquine-resistant Plasmodium falciparum isolates from the Sudan lack two mutations in the pfmdr1 gene thought to be associated with chloroquine resistance. Transactions of the Royal Society of Tropical Medicine and Hygiene 86, 578-589.

BASCO, L. K., LE BRAS, J., RHOADES, Z. \& WILSON, C. M. (1995). Analysis of pfmdr1 and drug susceptibility in fresh isolates of Plasmodium falciparum from subSaharan Africa. Molecular and Biochemical Parasitology 74, 157-166.

COWman, A. F., Karcz, S., Galatis, D. \& CUlvenor, J. G. (1991). A P-glycoprotein homologue of Plasmodium falciparum is localised on the digestive vacuole.

Fournal of Cell Biology 113, 1033-1042.

DJimde, A., DOUMbo, o. K., CORTESE, J. F., KaYentao, K., Doumbo, s., Diourte, Y., COUlibaly, D., Dicko, A., SU, X., FIDOCK, D. A., NOMURA, T. \& Wellems, T. E. (2001). A molecular marker for chloroquine resistant falciparum malaria. New England Fournal of Medicine 344, 257-263.

DURAisingh, M. T., DRAKeley, C. J., MUlleR, O., BAILey, R., SNOUNOU, G., TARGETT, G. A. T., GREENWOOD, B. M. \& WARHURST, D. C. (1997). Evidence for selection for the tyrosine-86 allele of the $p f m d r 1$ gene in Plasmodium falciparum by chloroquine and amodiaquine.

Parasitology 114, 205-211.

DURAISINGH, M. T., VON SEIDLEIN, L. V., JEPSON, A., JONES, P., SAMbou, I., PINDER, M. \& WARHURST, D. C. (2000). Linkage disequilibrium between two chromosomally distinct loci associated with increased resistance to chloroquine in Plasmodium falciparum. Parasitology 121, 1-7.

EGGLESON, K. K., DUFFIN, K. L. \& GOLDBERG, D. E. (1999). Identification and characterization of Falcilysin, a metallopeptidase involved in hemoglobin catabolism within the malaria parasite Plasmodium falciparum. Fournal of Biological Chemistry 274, 32411-32417.

FIDOCK, D. A., NOMURA, T., COOPER, R. A., SU, X., TALlEY, A. K. \& Wellems, T. E. $(2000 a)$. Allelic modifications of the $c g 2$ and $c g 1$ genes do not alter the chloroquine response of the drug-resistant Plasmodium falciparum. Molecular and Biochemical Parasitology 110, 1-10.

FIDOCK, D. A., NOMURA, T., TALley, A. K., COOPER, R. A., DZEKUNOV, S. M., FERDIG, M. T., URSOS, L. M. B., SIDHU, A. s., NAUde, B., Deitsch, K. W., su, X., wootton, J. C., ROEPE, P. D. \& WELlEMS, T. E. $(2000 b)$. Mutations in the $P$. falciparum digestive vacuole transmembrane protein PfCRT and evidence for their role in chloroquine resistance. Molecular Cell 6, 861-871.

FOOTE, S. J., KYLE, D. J., MARTIN, S. K., ODUOLA, A. M. J., FORSYTH, K., KEMP, D. J. \& COWMAN, A. F. (1990).
Several alleles of the multidrug-resistance gene are closely linked to chloroquine resistance in Plasmodium falciparum. Nature, London 345, 255-258.

Grobusch, M. P., ADAGU, I. S., KREMSNER, P. G. \& WArhurst, D. C. (1998). Plasmodium falciparum: in vitro chloroquine susceptibility and allele specific PCR detection of $p f m d r 1^{\text {Asn }} 86^{\mathrm{Tyr}}$ polymorphism in Lambarene, Gabon. Parasitology 116, 211-217.

HiLl, W. G. \& RoBERTSON, A. (1968). The effects of inbreeding at loci with heterozygote disadvantage. Genetics 60, 615-628.

MAYNARD SMITH, J. (1989). Evolutionary Genetics. Oxford University Press, Oxford.

PETERs, w. (1998). Drug resistance in malaria parasites of animals and man. Advances in Parasitology 41, $1-62$.

POVOA, M. M., ADAGU, I. S., Oliveira, S. G., Machado, R. L., Miles, M. A. \& WARhuRST, D. C. (1998). Pfmdr1 Asn1042Asp and Asp 1246Tyr polymorphisms, thought to be associated with chloroquine resistance, are present in chloroquine-resistant and -sensitive Brazilian field isolates of Plasmodium falciparum. Experimental Parasitology 88, 64-68.

REED, M. B, SAliba, K. J., CARUana, S. R., KirK, K. \& Cowman, A. F. (2000). Pgh1 modulates sensitivity and resistance to multiple antimalarials in Plasmodium falciparum. Nature, London 403, 906-909.

SOKHNA, C. S., MOLEZ, J. F., NDIAYE, P., SANE, B. \& TRAPE, J. F. (1997). In vivo chemosensitivity tests of Plasmodium falciparum to chloroquine in Senegal: the development of resistance and the assessment of therapeutic efficacy. Bulletin de la Société de Pathologie Exotique 90, 83-89.

SU, X., KiRKMAN, L. A., FUjIOKA, H. \& WELlems, T. E. (1997). Complex polymorphisms in a $\sim 300 \mathrm{kDa}$ protein are linked to chloroquine-resistant $P$. falciparum in Southeast Asia and Africa. Cell 91, 593-603.

SU, X., FERdig, M. T., HUANG, Y., HUYNh, C. Q., LiU, A., you, J., Wootton, J. C. \& Wellems, T. E. (1999). A genetic map and recombination parameters of the human malaria parasite Plasmodium falciparum. Science 286, 1351-1353.

Trape, J. F., Pison, G., Preziosi, M. P., ENEl, C., Desgrees DU LOU, A., DElaUmaY, V., SAMB, B., LAGaRde, E., MOLEZ, J. F. \& SIMONDON, F. (1998). Impact of chloroquine-resistance on malaria mortality. Comptes Rendus de l'Academie des Sciences 321, 689-697.

WEllems, T. E., PANTON, L. J., GluZMan, I. Y., DO ROSARIO, V. E., GWADZ, R. W., WALKER-JONAH, A. \& KROGSTAD, D. J. (1990). Chloroquine-resistance not linked to mdr-like genes in a Plasmodium falciparum cross. Nature, London 345, 253-255.

Wellems, T. E., WOOTTON, J. C., FUjIOKA, H., SU, X., COOPER, R., BARUCH, D. \& FIDOCK, D. A. (1998). P. falciparum $\mathrm{CG} 2$, linked to chloroquine resistance, does not resemble $\mathrm{Na}+/ \mathrm{H}+$ exchangers. Cell 94, 285-286.

WILSON, C. M., VOLKMAN, s. K., THAithong, s., MARTin, R. K., KYLE, D. E., Milhous, W. K. \& WiRTH, D. F. (1993). Amplification of pfmdr 1 associated with mefloquine and halofantrine resistance in Plasmodium falciparum from Thailand. Molecular and Biochemical Parasitology 57, 151-160. 
ZHANG, L., DRESSER, M. J., CHUN, J. K., BABBITT, P. C. \& GiACOMINi, K. M. (1997). Cloning and functional characterization of a rat renal organic cation transporter isoform (rOCT1A). Fournal of Biological Chemistry 272, 16548-16554.

ZUCKER, J. R., LACKRITZ, E. M., RUEBUSH, T. K.,
HIGHTOWER, A. W., ADUNGOSI, J. E., WERE, J.B., METCHOCK, B., PATRick, E. \& CAMPBELl, C. C. (1996). Childhood mortality during and after hospitalization in Western Kenya: effect of malaria treatment regimes. American Fournal of Tropical Medicine and Hygiene 55, 655-660. 